\section{Wozu noch Standespolitik?}

Vermutlich gehören Sie, liebe Leserin, lieber Leser, zu den vielen Mitgliedern unserer Organisation, die sich um Standespolitik nicht gross kümmern, ja sogar offen ihr Desinteresse gestehen. Das kann man Ihnen nicht verübeln, denn welche Anreize bietet schon eine Tätigkeit, die verglichen mit den verlockenden Karriereperspektiven oder auch heute noch ansehnlichen Verdienstmöglichkeiten doch eher unattraktiv wirken? Man könnte sogar böse nachfragen, was Standespolitik denn überhaupt bewirke. Denn: welche Rahmenbedingungen sind nicht schon durch Gesetze, Verordnungen und die Macht des Faktischen vorgegeben?

Der Einwand ist sicher bis zu einem gewissen Grad berechtigt. Es ist ja sogar eine stehende Redewendung, dass "die da oben machen, was sie wollen». Was bei einer solchen verkürzten Sichtweise untergeht, ist, dass sehr viele Bereiche der ärztlichen Tätigkeit - und dies nicht erst seit gestern - nur deshalb bestehen, weil sie einer vernünftigen und effizienten Selbstregulierung unterworfen sind.
Was sich so leicht als Selbstregulierung bezeichnen lässt, ist alles andere als eine Selbstverständlichkeit und bedeutet schon gar nicht, dass sich irgendetwas von selbst reguliere - von selbst geht gar nichts, auch in der Standespolitik nicht. Als Selbstregulierung verstandene Standespolitik bedeutet ganz im Gegenteil ein hohes Mass an Selbstverantwortung und freiwilliges Engagement. Dies nicht zuletzt aufder Stufe einer Fachgesellschaft oder einer kantonalen Ärztegesellschaft. Was in diesen Bereichen geleistet wird, kommt zwar nicht in die Schlagzeilen und wird wohl nur deshalb so wenig zur Kenntnis genommen, weil diese Arbeiten über weite Strecken reibungslos funktionieren. Dies dank dem Einsatz von Kolleginnen und Kollegen, deren Arbeitstag auch nur 24 Stunden hat.

Stellvertretend für all diese standespolitisch tätigen Ärztinnen und Ärzte äussert sich in dieser Ausgabe der Berner Kantonalpräsident Dr. Reinhold Streit, der nach neun Jahren Präsidialzeit das Amt in jüngere Hände übergeben hat. In seinen Äusserungen kommt das breite, abwechslungsreiche Spektrum der Aufgaben deutlich zum Ausdruck. Lassen Sie sich durch sein Beispiel verführen und verwerfen Sie nicht zum vorneherein den Gedanken an eine mögliche standespolitische Karriere.

Reto Steiner, Redaktor der $S \ddot{A} Z$ 